\title{
PERAN STRATEGIS PENERAPAN KONSEP SISTER CITY DALAM MENCIPTAKAN SURABAYA GREEN-CITY
}

\author{
Inggang Perwangsa Nuralam \\ Jurusan Administrasi Bisnis Universitas Brawijaya, Malang 65145, email:ing.nuralam@ub.ac.id
}

\begin{abstract}
Indonesia has many big cities with dynamic urbanization trend, increased economic growth and activities, rapid population growth, and dense populations such as Jakarta, Bandung, Medan, Surabaya and Balikpapan. As a result, the complex activities of people in urban areas need space and these needs cause environmental degradation, such as the practice of throwing garbage that is not in place. To prevent this in the future, it is important for developing countries like Indonesia to have benchmarks. Benchmarks for developing countries can come from developed countries. So far inter-city development usually has partnerships with cities abroad, including the sister city concept. Sister city practices can be used by cities in Indonesia for the development of good practices. The collaboration of Surabaya (Indonesia) with Kitakyushu (Japan) focuses a lot on creating urban planning that is environmentally sound or commonly known as green city or eco-city.
\end{abstract}

Keywords: Sister City, Surabaya, Kitakyushu, Trash, Green City

\begin{abstract}
abstrak
Indonesia memiliki banyak kota besar dengan tren urbanisasi yang lebih dinamis, peningkatan pertumbuhan ekonomi dan aktivitas, pertumbuhan penduduk yang cepat, dan populasi padat seperti Jakarta, Bandung, Medan, Surabaya dan Balikpapan. Akibatnya, kegiatan kompleks orang-orang di daerah perkotaan membutuhkan ruang dan kebutuhan ini menyebabkan degradasi lingkungan, seperti praktik buang sampah yang tidak pada tempatnya. Untuk mencegah hal ini di masa depan, penting bagi negara-negara berkembang seperti Indonesia untuk memiliki tolok ukur. Patokan untuk negara-negara berkembang dapat berasal dari negara-negara maju. Sejauh ini pembangunan antar kota biasanya memiliki kemitraan dengan kota-kota di luar negeri, termasuk konsep sister city. Praktek sister city dapat digunakan oleh kota-kota di Indonesia untuk pengembangan praktik yang baik. Kerjasama Surabaya (Indonesia) dengan Kitakyushu (Jepang) banyak fokus pada penciptaan tata kota yang berwawasan lingkungan atau yang biasa dikenal dengan istilah green city atau eco-city.
\end{abstract}

Kata kunci: Sister City, Surabaya, Kitakyushu, Sampah, Green City

\section{PENDAHULUAN}

Kerentanan lingkungan di kota besar dapat dilihat dari padat dan besarnya populasi, pertumbuhan ekonomi yang cepat, dan konversi penggunaan lahan. Beatley (2012), Birkmann et al. (2010), dan Hanson et al. (2011) berpendapat bahwa penggunaan lahan yang tinggi adalah contoh pembangunan kota yang tidak terkendali dan telah menjadi pendorong utama yang menyebabkan degradasi lingkungan. Peristiwa alam seperti kenaikan permukaan laut, cuaca ekstrim, banjir pesisir, dan tanah longsor telah menunjukan intensitas yang tidak teratur dalam pola dan frekuensi (Coumou dan Robinson, 2013; Hansen, 2010; Jongman et al., 2012).

Dalam mengantisipasi hal tersebut, kapasitas kota perlu ditingkatkan, salah satunya melalui perencanaan dan praktik tata kota yang baik. Beatley (2012), Broto dan Bulkeley (2013) menyadari bahwa kebijakan seperti pengaturan penggunaan lahan hijau, penyediaan insfrastruktur perkotaan yang baik, dan penyadaran penduduk tentang bahaya alam yang diakibatkan oleh ulah manusia, perlu menjadi perhatian serius bagi pemerintah lokal. Terutama pencemaran yang dilakukan dalam keseharian kaum urban berupa sampah.

Tren urbanisasi yang dinamis ditandai adanya peningkatan pertumbuhan ekonomi dan aktifitas, pertumbuhan penduduk yang cepat, dan populasi padat seperti Jakarta, Bandung, Medan, Surabaya, dan Balikpapan (Jones, 2002). Studi oleh Oberman et al. (2012) 
menunjukkan bahwa laju pertumbuhan percepatan baru-baru ini terjadi di kota-kota berukuran sedang di Indonesia.

Untuk mengantisipasi pencemaran lingkungan, penting bagi pemerintah untuk memiliki patokan pengelolaan kota lain sebagai pembelajaran prihal inisiasi dan program yang telah berhasil diimplementasikan dalam mengendalikan pencemaran lingkungan. Sejauh ini, kolaborasi antar kota difasilitasi dalam penerapan konsep sister city (Tjandradewi and Marcotullio, 2009). Secara umum, konsep sister city atau biasa disebut dengan kota kembar adalah kerjasama yang secara formal disetujui dan diikat dalam jalan panjang yang dilakukan oleh 2 kota di negara berbeda. Kerjasama yang dilakukan dalam konsep ini bisa berupa ekonomi, sosial-budaya, dan lingkungan dan bencana.

Pertanyaan dalam tulisan ini adalah sejauh mana konsep sister city dapat membantu kota menjadi kota yang tangguh dan responsiv dalam menangani permasalahan lingkungan. Surabaya dipilih dalam tulisan ini karena mewakili kota besar di Jawa Timur, dimana dalam beberapa tahun terakhir Walikota Surabaya giat dalam membangun infrastruktur dalam upayanya menciptakan green city atau yang biasa dikenal dengan ecocity. Green city atau eco-city adalah kota yang dirancang dengan pertimbangan untuk dampak sosial, ekonomi, lingkungan, dan tangguh bagi populasi yang ada, tanpa mengorbankan kemampuan generasi mendatang untuk mengalami hal yang sama (Register, 2006).

Dalam perspektif nilai bisnis, beberapa hal yang bisa kita ambil manfaatnya dalam penerapan konsep eco-city adalah peningkatan investasi hijau; peningkatan kualitas dan kuantitas pekerjaan pada sektor hijau; dan penurunan biaya produksi yang disertai dengan peningkatan revenue. Dengan konsep ini, maka diharapkan pelaku usaha mempu mengelola sumberdaya alam dan lingkungan menjadi lebih baik dan berorientasi ramah lingkungan.

\section{KAJIAN LITERATUR}

Sister city, sister cities, twin city merupakan konsep kerjasama antar dua kota, dua propinsi, ataupun dua negara yang berbeda lokasi dan administrasi politik dengan tujuan menjalin hubungan budaya, ekonomi, dan kontak sosial antar penduduk secara berkesinambungan. Secara umum, sister city adalah adanya dua buah kota yang secara resmi saling terikat dengan suatu tujuan tertentu, baik itu mempromosikan perdamaian, pertemanan, ataupun perasaan saling mengerti antara orangorang yang berada didalamnya (Souder et al., 2005). Sister city juga digunakan untuk mendorong hubungan perdagangan dan pariwisata di kedua wilayah (Clarke, 2009; Kaltenbrunner et al., 2013).

Penekanan yang semakin besar pada globalisasi telah membawa analisis kota-kota global menjadi fokus yang tajam, utamanya dalam peningkatan daya saing (Villers, 2009). Sister city menyediakan tempat dalam menganalisis adanya hubungan antar kedua pihak lokal dalam lingkungan global. Awalnya dipahami sebagai sarana pasca perang untuk mengembangkan persahabatan dan ikatan budaya, sister city didasarkan pada persamaan seperti nama atau fungsi ekonomi. Baru-baru ini, pengakuan yang lebih besar telah diberikan kepada ekonomi dan manfaat dari koneksi ini (Cremer et al., 2001)

Mayoritas hubungan sister city saat ini terjalin di Eropa setelah perang dunia kedua. Dengan berpegang pada prinsip, "masyarakat yang saling mengenal maka tidak akan saling membenci", sister city diharapkan bisa berkonstribusi pada perdamaian dunia kedepannya (Souder et al., 2005). Sister City Organization, sebuah organisasi yang mewadahi hubungan kerjasama antara sister city, mendefisinikannya sebagai suatu kemitraan jangka panjang antara dua komunitas masyarakat di dua negara yang secara resmi diakui apabila kedua komunitas tersebut menandatangani suatu perjanjian (SCI, 2012).

Tjandradewi (2006) membahas tiga faktor yang dapat memajukan pengembangan hubungan trans-nasional dan sub-nasional. Pertama, kota-kota yang berkembang pesat di negara berkembang yang membutuhkan bantuan harus secara aktif mencari untuk itu. Pemerintah setempat telah mencari pengaturan kemitraan dengan rekan-rekan di negara maju dengan harapan pengetahuan teknis dan transfer keterampilan (Kearns \& Paddison, 2000). Kedua, globalisasi telah menawarkan peluang bagi negara-negara berkembang dan kota untuk berbagi informasi penting di antara mereka dan warga mereka, teknologi informasi canggih, arus global, termasuk orang, informasi dan pengetahuan. Ketiga, desentralisasi dan bentuk-bentuk baru 
Inggang Perwangsa Nuralam, peran strategis penerapan konsep sister city ...

hubungan antar pemerintah antara pemerintah lokal dan nasional telah menyediakan lingkungan yang kondusif untuk kerjasama lokal lintas batas.

\section{A. Tipe Hubungan Sister City}

Secara budaya, pertukaran budaya seperti pertujukkan seni lukis, musik, ataupun pameran dilakukan di sister city agar terjalin rasa saling mengerti budaya satu sama lain. Penelitian Bell menemukan bahwa hubungan yang banyak terjadi adalah hubungan akamedik dalam bentuk pertukaran pelajar (Souder et al., 2005). Dengan mengirimkan para pemuda dari satu kota ke kota lain, ataupun menerima pemuda dari kota lain, dapat menjadi investasi jangka panjang. Ketika para pemuda tersebut sudah beranjak dewasa, mereka sadar bahwa ada kota lain diluar sana yang memiliki kesamaan dengan kota dimana mereka berasal.

Studi yang dilakukan oleh Ramasamy dan Cremer (1998) membuktikan bahwa budaya telah dianggap menjadi faktor penting yang mempengaruhi perdagangan lintas batas dan investasi. Konsep hubungan sister city sebagai instrumen yang efektif untuk mendorong hubungan budaya dan ekonomi yang lebih erat antar negara. Penekanannya adalah pada pendekatan yang terintegrasi, berdasarkan pada hubungan yang beraneka ragam antara budaya dan perdagangan. Pendekatan eksklusif, yang mengikuti agenda budaya atau komersial, dipertanyakan (Ramasamy dan Cremer, 1998).

Bontenbal dan van Lindert (2009),

Tjandradewi dan Marcotullio (2009) menjelaskan bahwa desentralisasi dan globalisasi telah mendorong peningkatan perhatian dan kapasitas pemerintah daerah di Indonesia dalam tata pemerintahan yang baik sebagai prasyarat untuk pembangunan, serta kerja sama yang lebih luas. Kedua hal ini mendorong instrumen kerjasama pembangunan untuk saling membantu dalam mengelola kota dan memenuhi kebutuhan dengan cara berbagi pengetahuan, sumber daya, teknologi, dan keahlian antar kota.

Konsep asli dari kota kembar adalah untuk meningkatkan pengertian dan perdamaian internasional di tingkat lokal. Selama bertahun-tahun, konsep itu telah berubah dan sekarang ada perdebatan kuat atas masuknya pertukaran komersial ke dalam hubungan tipe kota kembar (O'Toole, 2001).
Tujuan kemitraan sister city adalah untuk menyatukan orang-orang untuk menumbuhkan saling pengertian, dan mengembangkan saling manfaat melalui berbagi pengetahuan dan peluang baru seperti layanan pendidikan, aksi politik dan rekreasi budaya (Shaw dan Karlis, 2002).

\section{B. Prinsip Kesamaan Sister City}

Untuk menjalin hubungan dengan kota yang akan menjadi sister city, ada beberapa prinsip yang dijadikan acuan meskipun antara satu kota dengan kota lainnya prinsip ini dapat berbeda-beda (Kelowna, 2010). Prinsip-prinsip tersebut antara lain: 1) Similaritas - adanya kesamaan bersama; 2) Pertukaran - adanya potensi pertukaran dalam segi budaya, edukasi, rekreasi, ataupun ekonomi; 3) Hubungan timbal balik - pertukaran yang sifatnya positif harus berjalan dari dua arah; 4) Berorientasi pada masyarakat - adanya kepemimpinan yang aktif, keterlibatan dan dukungan oleh masyarakat, melalui organisasi ataupun bisnis yang sudah ada untuk membangun ataupun memelihara hubungan yang sudah ada; 5) Manfaat strategis - manfaat jangka pendek dan jangka panjang yang didapat dari hubungan melebihi biaya publik yang harus dikeluarkan untuk menjalin ataupun memilihara hubungan yang sudah ada; 6) Eksklusivitas \& Kedekatan - tidak memiliki hubungan sister city dengan kota lainnya di negara yang sama atau lokasi yang berdekatan dari lokasi calon sister city; 7) Kestabilan politik - kondisi politik yang stabil dinegara tempat sister city berada, sesuai dengan hasil pengumuman dari pemerintah pusat.

Dalam menjalin hubungan ini, terdapat sejumlah keuntungan dari kerjasama sister city, diantaranya adalah: (1) kesempatan untuk transfer knowledge dan experience dalam menegelola pembangunan terhadap bidang yang dikerjasamakan; (2) Mendorong munculnya ide dan peran aktif pemerintahdaerah kota serta stakeholder lainnya; (3) Mempererat persahabatan pemerintah dan masyarakat kedua belah pihak; (4) sebagai kesempatan transfer culture untuk memperkaya kebudayaan daerah. Namun disisi lain skema sister city juga menimbulkan beberapa faktor negatif, diantaranya adalah: (1) Meningkatnya beban keuangan negara atau daerah karena memakai dana APBN atau APBD, (2) cenderung menunggu fasilitasi dari pemerintah, (3) Memiliki potensi 
ketidaksetaraan dalam kerja sama yang kurang seimbang sehingga hanya menguntungkan satu pihak.

\section{Perkembangan Sister City di Indonesia}

Hingga saat ini, terdapat 47 kota dari seluruh 33 provinsi yang pernah dan memiliki hubungan sister city (Sitinjak et al., 2014). Tujuan utama dari program sister city baik antar kota yang ada di Indonesia maupun dengan kota di negara berkembang saat ini ialah untuk mengakselerasi pertumbuhan ekonomi antara kota-kota yang bersangkutan. Jakarta, misalnya, memiliki jumlah sister city terbanyak dengan jumlah 49 sister city pada tahun 2014 dengan 21 diantaranya kota-kota di luar negeri. Menurut Kementrian Luar Negeri, $20 \%$ dari total hubungan sister city yang ada di Indonesia memiliki hubungan yang sangat baik, $15 \%$ cukup baik dan $65 \%$ hampir tidak memiliki kegiatan sama sekali (Salam 2004). Salam (2004) menilai pemerintah Indonesia belum menganggap secara serius konsep pembelajaran dari sister city ini. Ide sister city juga mengalami beberapa sorotan kritik. Salah satu kritik tersebut fokus pada banyaknya hubungan yang secara ekonomi menguntungkan bagi kota tetapi program tersebut membutuhkan biaya dari kota untuk bisa berjalan.

Pemerintah Pusat membuat beberapa kebijakan dan program, agar Pemerintah Daerah dapat memanfaatkan hubungan ini sebagai upaya meningkatkan pertumbuhan dan pembangunan kota/daerah masing-masing. Skema sister city ini belum dikenal dan dipahami secara luas, bahkan Kementerian Dalam Negeri dan Pemerintah Daerah hanya memahami skema tersebut. Padahal, konsep skema yang diinginkan adalah hubungan kemitraan antar komunitas kota. Dilihat dari sejarah terbentuknya konsep dan skema sister city ini, sesungguhnya skema yang diinginkan adalah hubungan kemitraan antar komunitas kota, sehingga idealnya dilaksanakan secara sinergi antar stakeholders kota secara lengkap, yaitu pemerintah, dunia usaha, dan masyarakat.

\section{METODE}

Pengumpulan data akan mencakup pertanyaan dari setiap data yang relevan dengan kapasitas lokal. Tujuannya adalah mengidentifikasi daerah di mana kerjasama sister city dapat dilakukan dan jenis kegiatan dalam rangka kerjasama antara kedua daerah. Sumber data yang digunakan dalam penelitian ini adalah data sekunder. Sebuah sumber sekunder adalah sumber yang tidak langsung memberikan data kepada pengumpul data melalui orang lain atau melalui dokumen.

Sumber-sumber sekunder yang diperoleh dari literatur seperti jurnal ilmiah, buku, data dari Kedutaan Besar Indonesia untuk Jepang, serta dokumen lainnya yang terkait dengan penelitian ini, termasuk data dari website. Penelitian yang menggunakan data sekunder juga dapat berupa ringkasan, sintesa dari penelitian terdahulu (Crouch dan Housden, 2013). Data yang akan dikumpulkan seluruh penelitian bervariasi, mulai dari dokumen resmi pemerintah Informasi demografi lokal, karakteristik sosial-budaya dan kondisi ekonomi dan rencana pembangunan; persepsi pemerintah dan masyarakat tentang pembangunan; termasuk kegiatan sosial budaya dari masyarakat setempat.

\section{HASIL DAN PEMBAHASAN}

Surabaya pada awal tahun 2000, mengalami 'banjir sampah'. Hal ini terjadi dikarenakan warga menutup Lahan Pembuangan Akhir (LPA) Keputih, sehingga sampah berserakan di setiap sudut kota. Selain itu, sungai di kota Surabaya juga tercemar sehingga mengakibatkan warga mengalami kesulitan dalam memperoleh air bersih guna memenuhi kebutuhan sehari-hari dan timbul pula penyakit kulit. Pencemaran air ini berasal dari limbah industri dan rumah tangga.

Pemerintah Kota Surabaya menyadari bahwa kondisi tersebut tidak bisa dibiarkan, karena bila dibiarkan akan menimbulkan masalah-masalah lain yang lebih besar. Kesehatan masyarakat akan terganggu, begitu pula dengan keindahan kota. Pemerintah berusaha untuk mencari solusi yang tepat sasaran dan berkelanjutan.

Sementara, kota Kitakyushu terkenal sebagai Kota Asap, dan memiliki permasalahan yang sama dengan kota Surabaya berkaitan dengan sampah dan tercemarnya air sungai. Namun, setelah bertahun-tahun menjalankan program untuk memperbaiki lingkungannya, kota Kitakyushu kini telah menjadi kota yang bersih dan teratur. Bahkan warga di sana sudah dapat meminum air langsung dari keran-keran air di rumahnya. Hal ini yang mendorong Pemerintah Surabaya 
Inggang Perwangsa Nuralam, peran strategis penerapan konsep sister city ...

untuk bekerjasama dengan Pemerintah Kota Kitakyushu.

Kota Kitakyushu merupakan salah satu kota yang terletak di Pulau Kyushu, pulau ketiga terbesari di Jepang. Kota Kitakyushu, yang berarti Kyushu Utara, didirikan pada 10 Februari 1963. Kota ini merupakan salah satu bukti nyata keberhasilan penerapan konsep Low Carbon Society. Sebelum tahun 1960, kota Kitakyushu merupakan kota yang dikenal sebagai kota paling berpolusi akibat pencemaran industri. Langit Kitakyushu dipenuhi kabut asap industri sehingga berwarna keabu-abuan dan air pun tercemar limbah industri sehingga menimbulkan berbagai macam permasalah kesehatan. Sekarang, kota Kitakyushu berhasil menciptakan industri berbasis lingkungan dan sukses menemukan berbagai teknologi lingkungan canggih. Langit di kota Kitakyushu berwarna biru cerah dan sungainya pun jernih, tak lagi berwarna kehitaman, bahkan masyarakat Kitakyushu dapat meminum air langsung dari keran-keran air yang ada.

Atas keberhasilannya ini, kota Kitakyushu kemudian membentuk program kerjasama dengan berbagai macam kota di Asia berbasis lingkungan hidup. Salah satunya adalah dengan kota Surabaya, Indonesia. Program yang ditawarkan antara lain adalah program revitalisasi sungai, pengolahan sampah dan pembangunan lingkungan industri yang ramah lingkungan.

\section{A. Kerjasama Green Sister City}

Hubungan kerjasama Surabaya Kitakyushu, sesungguhnya telah terjalin sejak lama. Namun baru berjalan efektif selama beberapa tahun belakangan ini. Kerjasama ini tertuang dalam rencana Green Sister City, yang fokus dalam permasalah pengeloaan sampah, peningkatan kualitas air dan pengembangan partisipasi masyarakat.

Pengelolaan sampah direalisasikan dengan pembangunan tempat pembuangan sampah yang dilengkapi peralatan untuk memilah sampah di Depo Sutorejo, Surabaya, pada tahun 2013. TPS Sutorejo ini menampung sampah domestik (rumah tangga) dari kecamatan Mulyorejo, Sutorejo dan Kalisari. Pembangunan ini merupakan hasil pembelajaran dari kota Kitakyushu yang telah melakukan pengelolaan sampah dengan program 3R (Reuse, Reduce, Recycle). Di TPS Sutorejo disediakan conveyor untuk membawa sampah yang masuk untuk dipilah oleh petugas TPS. Pemilahan sampah ini dibagi menjadi sampah organik dan anorganik. Untuk sampah organik akan dikelola di bagian pengolahan sampah organik, untuk dapat diolah menjadi pupur kompos.

Pupuk kompos ini kemudian digunakan untuk perawatan pohon dan tanaman yang ada di Surabaya, hingga kini taman-taman di Surabaya menjadi subur dan indah. Sedangkan untuk sampah anorganik disortir kembali menjadi sampah plastik, kerdus atau kertas, botol dan sampah yang tidak bisa diolah. Untuk sampah yang tidak bisa diolah akan dikirim ke tempat pembuangan sampah akhir, sedangkan sisanya dapat dijual ke pengepul. Depo Sutorejo ini terbukti dapat mengurangi sampah di wilayah Sutorejo sebanyak 50\%.

TPS Sutorejo ini mengadopsi TPS yang berada di Kitakyushu yang dikelola oleh Beetle Nisihara Co. Ltd., yang telah berpengalaman dalam bidang pengelolaan sampah hingga mendapat sertifikat ISO 14001 (environmental management system). Beetle Nisihara Co. Ltd. dapat menampung sampah sejumlah 60 ton per hari, atau setara dengan 20 truk sampah. Namun, pengelolaan dapat berlangsung cepat karena adanya peran serta masyarakatnya. Masyarakat di Kitakyushu memiliki kesadaran untuk membuang sampah pada tempatnya serta memilah-milah terlebih dahulu sampah berdasarkan jenisnya, seperti sampah organik dan anorganik, sampah kertas atau kardus dan sampah plastik.

\section{B. Rencana Kerjasama yang akan Dilaksanakan}

Dalam pengelolaan limbah cair dan peningkatan kualitas air, Pemerintah SurabayaKitakyushu berencana untuk membangun alat instalasi penjernihan air di Surabaya. Di Kitakyushu, proyek instalasi air ini sudah berhasil dilaksanakan, sehingga warga di sana sudah dapat meminum air langsung dari kerankeran air di rumah. Namun, alat instalasi air ini tidak bisa langsung digunakan di Surabaya, disebabkan perbedaan sumber dan jenis air di Kitakyushu dan Surabaya. Untuk itu dibutuhkan penelitian, yang sudah dijalankan sejak tahun 2014 dan rencananya akan berakhir pada awal tahun 2016 mendatang. Bila penelitian ini sudah selesai, pihak Kitakyushu akan mengembangkan alat instalasi air yang sesuai dengan jenis air di Surabaya, hingga 
nantinya warga Surabaya dapat menikmati air minum langsung dari keran air di rumah dan di area-area publik.

Selain itu, Kitakyushu juga berencana untuk membuat alat pembangkit listrik dari sampah yaitu dengan membuat pabrik insicerator di wilayah Surabaya, serta membangun pembangkit energi di kawasan industri melalui proyek powerplan Kitakyushu \& Surabaya Smart Community (KS2C). Pihak Kitakyushu mengusung metode $\mathrm{Co}$-Generation System yang lebih ramah lingkungan karena berbahan gas. Pembangkit energi ini akan dapat menghasilkan listrik dan uap. Namun proyek KS2C ini masih dalam masa penjajakan.

Melalui kerjasama dengan Kitakyushu, Surabaya sudah mengalami perkembangan yang baik. Dari awalnya merupakan kota yang penuh dengan sampah dan sungai yang tercemar, kemudian menerapkan sistem pengelolaan sampah yang baik sehingga berhasil mengurangi volume sampah yang ada dan memenangkan piala Adipura sebagai kota terbersih. Kemudian, Surabaya akan melanjutkan proses kerjasama melalui rencana program powerplant di kawasan industri (Kitakyushu-Surabaya Smart Community), program pembangkit listrik tenaga sampah, serta pembangunan instalasi penjernih air.

\section{Nilai Bisnis dari Konsep Sister City}

Kerjasama yang dilakukan oleh pemerintah kota Surabaya dengan kota Kitakyushu menjadi strategis dalam menginisiasi munculnya komunitas hijau (green community) bukan hanya dari sisi konsumen namun juga produsen. Pemangku kepentingan yang terlibat dalam komunitas tersebut melibatkan pemerintah, pelaku usaha, masyarakat dalam pembangunan kota hijau kalangan bisnis dan kalangan masyarakat dalam pembangunan kota hijau.

Penciptaan nilai bisnis yang berorientasi lingkungan menjadi alternatif bagi perusahaan dalam menciptakan keunggulan bersaing yang efektif dan menjadikan perusahaan sukses secara global. Di kota-kota besar dunia, potensi eco-city menjadi hal potensial untuk dijajaki kerjasama antar kedua negara, utamanya dalam peluang bisnis dan investasi pada sektor manufaktur, transportasi, pusat perbelanjaan, pendidikan, perkantoran, dan insfrastruktur yang berorientasi lingkungan. Beberapa proyek bisnis dalam eco-city yang berhasil menarik investasi besar diantaranya Songdo International Business District (investasi US\$40 miliar) Seoul, Korea Selatan; Roppongi Hills (US\$4 miliar) Tokyo, Jepang; Clark Green City (US\$59,3 miliar) Capas, Tarlac, Filipina; Centenary City Nigeria (US\$18 miliar) Nigeria; dan Meikarta (Rp278 triliun) Cikarang, Indonesia.

\section{SIMPULAN DAN SARAN}

\section{A. Kesimpulan}

Penelitian ini akan mencoba telah menggambarkan hubungan Sister city yang dilakukan Kota Surabaya di Indonesia dengan Kota Kitakyushu di Jepang. Arti penting dari penelitian ini adalah untuk mengidentifikasi kesamaan antara dua daerah yang potensial untuk kerjasama antar daerah dan selanjutnya membantu perkembangan mereka. Hasil penelitiannya adalah untuk membuat hubungan yang baik dan mengambil keuntungan dengan ini sister city yaitu penataan kota yang berwawasan lingkungan (green city). Beberapa hal yang bisa disimpulkan dalam penelitian ini adalah: pertama, sister city adalah salah satu model kerjasama mikro digunakan oleh dua kota di jalur diplomasi bilateral yang berfokus pada peningkatan pembangunan di kedua kota/negara. Dasar dari konsep sister city dilakukan dalam atas dasar kesamaan administrasi, karakteristik sosial-budaya atau geografis atau kesamaan dalam masalah yang dihadapi oleh publik. Dalam era globalisasi, interkonektivitas antar negara akan menjadi alat untuk mengembangkan potensi lokal dan memecahkan masalah lokal.

Kedua, khusus program kerjasama sister city, inisiatif kerjasama ini tidak hanya dapat dilakukan dari kota negara lain, tapi dapat juga dilakukan oleh kota di dalam negeri yang setara. Hal ini dapat dilakukan apabila penjajakan kerjasama sister city mempertimbangkan kepentingan bagi pembangunan dan pengembangan kota secara menyeluruh. Kementerian Dalam Negeri, misalnya, pernah menetapkan Kota Surabaya sebagai kota berprestasi dan sukses sebagai best practice sister city di Indonesia, khususnya dalam perencanaan, prosedur, dan regulasi kerjasama dengan luar negeri.

\section{B. Saran}

Kerjasama sister city, semestinya dikemas dengan tujuan jangka panjang, dalam rangka mengembangkan kapasitas SDM, 
Inggang Perwangsa Nuralam, peran strategis penerapan konsep sister city ...

kapasitas pemerintah daerah, dunia usaha, dan masyarakat kota, sehingga dapat meningkatkan fundamental ekonomi untuk pengembangan ekonomi daerah. Kota/Daerah dapat memanfaatkan hubungan sister city untuk memacu pertumbuhan dan pembangunan kota/daerahnya masing-masing.

\section{DAFTAR PUSTAKA}

Beatley, T. (2012). Planning for coastal resilience: Best practices for calamitous times. Island Press.

Birkmann, J., Garschagen, M., Kraas, F., \& Quang, N. (2010). Adaptive urban governance: new challenges for the second generation of urban adaptation strategies to climate change. Sustainability Science, 5(2), 185-206.

Bontenbal, M., \& van Lindert, P. (2009). Transnational city-to-city cooperation: Issues arising from theory and practice. Habitat International, 2(33), 131-133.

Broto, V. C., \& Bulkeley, H. (2013). A survey of urban climate change experiments in 100 cities. Global environmental change, 23(1), 92-102.

Clarke, N. (2009). In what sense 'spaces of neoliberalism'? The new localism, the new politics of scale, and town twinning. Political Geography, 28(8), 496-507.

Coumou, D., \& Robinson, A. (2013). Historic and future increase in the global land area affected by monthly heat extremes. Environmental Research Letters, 8(3), 034018.

Cremer, R. D., De Bruin, A., \& Dupuis, A. (2001). International Sister- Cities: Bridging the Global- Local Divide. American Journal of Economics and Sociology, 60(1), 377-401.

Crouch, Sunny., and Matthew Housden (2003). Marketing research for managers; The Marketing Series; Chartered Institute of Marketing. Butterworth-Heinemann. p. 22. ISBN 0750654538.

Hansen, H. S. (2010). Modelling the future coastal zone urban development as implied by the IPCC SRES and assessing the impact from sea level rise. Landscape and Urban Planning, 98(3-4), 141-149.

Hanson, S., Nicholls, R., Ranger, N., Hallegatte, S., Corfee-Morlot, J., Herweijer, C., \& Chateau, J. (2011). A global ranking of port cities with high exposure to climate extremes. Climatic change, 104(1), 89-111.

Jones, G. W. (2002). Southeast Asian urbanization and the growth of megaurban regions. Journal of Population Research, 19(2), 119-136.

Jongman, B., Ward, P. J., \& Aerts, J. C. (2012). Global exposure to river and coastal flooding: Long term trends and changes. Global Environmental Change, 22(4), 823-835.

Kaltenbrunner, A., Aragón, P., Laniado, D., \& Volkovich, Y. (2013). Not all paths lead to Rome: Analysing the network of sister cities. In International Workshop on Self-Organizing Systems (pp. 151-156). Springer, Berlin, Heidelberg.

Kearns, A., \& Paddison, R. (2000). New challenges for urban governance. Urban Studies, 37(5-6), 845-850.

Kelowna, C. O. (2010). Council Policy of Sister Cities. C. Services. Kelowna.

Oberman, R., Dobbs, R., Budiman, A., Thompson, F., \& Rossé, M. (2012). The archipelago economy: Unleashing Indonesia's potential. McKinsey Global Institute.

O'Toole, K. (2001), "Kokusaika and internationalisation: Australian and Japanese Sister City type relationships", Australian Journal of International Affairs, Vol. 55 No. 3, pp. 403- 19.

Ramasamy, B. and Cremer, R. (1998), “Cities commerce and culture: the economic role of international sister-city relationships between New Zealand and Asia", Journal of the Asia pacific Economy, Vol. 3 No. 3, pp. 446- 61.

Register, R. (2006). Ecocities: Rebuilding cities in balance with nature. New Society Publishers. 
Salam, U. (2004). Dinamika Kerjasama Internasional Provinsi di Indonesia dengan Luar Negeri. Makalah Lokakarya Cara Penanganan Kerjasama Internasionl, 7.

Shaw, S., \& Karlis, G. (2002). Sister-city partnerships and cultural recreation: The case of Scarborough, Canada and Sagamihara, Japan. World Leisure Journal, 44(4), 44-50.

Sister Cities International (SCI), 2012. www.sistercities.org/sites/default/files/SCI_2012_ Annual_Report.pdf. Diakses pada 1 April 2017.

Sitinjak, Efraim; Saut Sagala dan Elisabeth Rianawati., 2014. Opportunity for Sister City Application to Support Resilience City. Working Paper Series.
No. 8, May 2014. Resilience Development Initiative.

Souder, D. B., Bredel, S., \& Rodd, L. R. (2005). A Study of Sister City Relations. A research paper of Asian Languages and Civilizations in University of Colorado.

Tjandradewi, B. I. (2006). Evaluation of cityto-city cooperation: case study experiences within Asia (Doctoral dissertation, $\mathrm{Ph}$. D. Dissertation, Department of Urban Engineering, University Of Tokyo, Tokyo).

Tjandradewi, B. I., \& Marcotullio, P. J. (2009). City-to-city networks: Asian perspectives on key elements and areas for success. Habitat International, 33(2), 165-172. 